DR. BARIS GENCER (Orcid ID : 0000-0002-8954-9694)

Article type : Original Paper

\title{
Prognostic Value of Elevated Lipoprotein(a) In Patients With Acute Coronary Syndromes
}

Baris Gencer, MD 1 II; Fabio Rigamonti, $\mathrm{MD}^{1}$; David Nanchen, MD, MS²; Nicolas Vuilleumier, $\mathrm{MD}^{3}$; Ilse Kern, $\mathrm{MD}, \mathrm{PhD}^{3}$, Soheila Aghlmandi, $\mathrm{PhD}^{4}$; Roland Klingenberg, $\mathrm{MD}^{5}$; Lorenz Räber, MD, $\mathrm{PhD}^{6}$; Reto Auer, MD, MAS ${ }^{7}$; David Carballo, MD, MPH${ }^{1}$; Sebastian Carballo, MD, $\mathrm{PhD}^{8}$; Dik Heg, $\mathrm{PhD}^{4}$; Stephan Windecker, $\mathrm{MD}^{6}$; Thomas Felix Lüscher, MD ${ }^{9,}{ }^{10}$; Christian M. Matter, $\mathrm{MD}^{5}$; Nicolas Rodondi, MD, MAS ${ }^{7,11}$; François Mach, MD ${ }^{1}$

${ }^{1}$ Cardiology Division; Geneva University Hospitals, Switzerland

${ }^{2}$ Department of Ambulatory Care and Community Medicine, Lausanne University, Switzerland

${ }^{3}$ Division of Laboratory Medicine, Geneva University Hospitals, Geneva, Switzerland.

${ }^{4}$ Institute of Social and Preventive Medicine, and Clinical Trials Unit, Department of Clinical Research, University of Bern, Switzerland

${ }^{5}$ Department of Cardiology, University Heart Center, University Hospital Zurich, Switzerland

${ }^{6}$ Department of Cardiology, University Hospital of Bern, Switzerland

${ }^{7}$ Institute of Primary Health Care (BIHAM), University of Bern, Switzerland

${ }^{8}$ Department of Internal Medicine, Geneva University Hospitals

${ }^{9}$ Center for Molecular Cardiology, University of Zurich

${ }^{10}$ Cardiology, Royal Brompton and Harefield Hospital and Imperial College London, United Kingdom

${ }^{11}$ Department of General Internal Medicine, Inselspital, Bern University Hospital, University of Bern, Switzerland

This article has been accepted for publication and undergone full peer review but has not been through the copyediting, typesetting, pagination and proofreading process, which may lead to differences between this version and the Version of Record. Please cite this article as doi: $10.1111 /$ eci. 13117

This article is protected by copyright. All rights reserved. 


\title{
ITCorresponding author:
}

Baris Gencer, MD

Current Office: TIMI Study Group, Brigham and Women's Hospitals, Harvard Medical School. Office Level One, 350 Longwood Ave, Boston, MA 02215.

Home Office Address: Cardiology Division, Geneva University Hospitals, Rue Gabrielle Perret

Gentil 4, 1205 Geneva, Switzerland.

Phone: +1 (857) 891- 6864 OR +41 (78) 8056277 .

Email: baris.gencer@hcuge.ch or bgencer@bwh.harvard.edu.

\begin{abstract}

\section{Background}

Minimal lipoprotein(a) [Lp(a)] target values are advocated for high-risk cardiovascular patients. We investigated the prognostic value of $\mathrm{Lp}(\mathrm{a})$ in the acute setting of patients with acute coronary syndromes (ACS).
\end{abstract}

\section{Methods}

Plasma levels of $\mathrm{Lp}(\mathrm{a})$ were collected at time of angiography from 1711 patients hospitalized for ACS in a multicenter Swiss prospective cohort. Associations between elevated Lp(a) $\geq 30 \mathrm{mg} / \mathrm{dL}$ (cut-off corresponding to the $75^{\text {th }}$ percentile of the assay) or $\mathrm{Lp}$ (a) tertiles at baseline, and major adverse cardiovascular events (MACE) at 1-year, defined as a composite of cardiac death, myocardial infarction or stroke were assessed using hazard ratios (HR) and $95 \%$ confidence intervals (CI) adjusting for traditional cardiovascular risk factors (age, sex, smoking, diabetes, hypertension, lowdensity lipoprotein cholesterol [LDL-C], high-density lipoprotein cholesterol [HDL-C] and triglycerides.

\section{Results}

Lp(a) levels range between $2.5 \mathrm{mg} / \mathrm{dL}$ to $132 \mathrm{mg} / \mathrm{dL}$ with a median value of $6 \mathrm{mg} / \mathrm{dL}$ and a mean value of $14.2 \mathrm{mg} / \mathrm{dL}$. A total of 276 patients $(23.0 \%)$ had $\mathrm{Lp}$ (a) plasma levels $\geq 30 \mathrm{mg} / \mathrm{dL}$ ). Patients with elevated $\mathrm{Lp}(\mathrm{a})$ were more likely to be of female gender, and to have higher levels of total cholesterol, LDL-C, HDL-C and triglycerides. Higher Lp(a) was associated with failure to reach the LDL-C target $<1.8 \mathrm{mmol} / \mathrm{l}$ at 1-year (HR 1.71, 95\% CI 1.13-2.58, $\mathrm{P}=0.01$ ). No association was found between elevated $\mathrm{Lp}(\mathrm{a})$ and MACE at 1 year (HR 1.05, 95\% CI 0.64-1.73), nor for $\mathrm{Lp}(\mathrm{a})$ tertiles (HR $0.82,95 \%$ CI $0.52-1.28, \mathrm{P}>0.20)$ or standardized continuous variables $(0.98,95 \% \mathrm{CI}$ 0.82-1.19 for each increase of standard deviation).

This article is protected by copyright. All rights reserved. 


\section{Conclusions}

Our real-world data suggest high $\operatorname{Lp}(\mathrm{a})$ levels at time of angiography are not predictive for cardiovascular outcomes in patients otherwise medically well controlled, but might be useful to identify patients who would not be on LDL-C targets one year after ACS.

\section{Introduction}

Lipoprotein(a) $[\mathrm{Lp}(\mathrm{a})]$ is a particle constituted of a low-density lipoprotein (LDL) with apolipoprotein B-100 (ApoB) bound to its surface and bound by a disulfide bridge to Apolipoprotein A (ApoA). ${ }^{1}$ Although the physiological function of $\operatorname{Lp}(\mathrm{a})$ has not been elucidated, mechanistic studies have shown it to play a pathogenic role in the process of atherothrombosis. ${ }^{2}$ Epidemiological and Mendelian randomization studies provide support for a causal association between $\operatorname{Lp}(\mathrm{a})$ levels and cardiovascular disease (CVD). ${ }^{3,4}$ It is estimated that $20 \%$ of the population has Lp(a) levels above $50 \mathrm{mg} / \mathrm{dL}$ and that the risk for CVD is increased by 2- to 2.5 -fold in individuals with levels above the 90th percentile. ${ }^{5}$ However, the cut-off is assay dependant and some studies suggested a cut-off of 24 $\mathrm{mg} / \mathrm{dL}$ or $36 \mathrm{mg} / \mathrm{dL}$ in populational studies. ${ }^{6}$

The European Society of Cardiology (ESC) guidelines recommend measuring Lp(a) levels in selected patients at intermediate or high risk of CVD and associate values above the cut-off of $50 \mathrm{mg} / \mathrm{dL}$ with a very high cardiovascular (CV) risk. ${ }^{7}$ Patients presenting with acute coronary syndromes (ACS) are at high risk of recurrent CVD events and need intensive lipid-lowering therapies to lower LDL cholesterol (LDL-C) and improve their prognosis. ${ }^{7}$ This is especially true for patients with familial hypercholesterolemia (FH) who have a higher risk for recurrence of CVD events after an ACS. ${ }^{8}$ In the secondary prevention setting, available data suggest a possible increase of CVD events with higher levels of $\operatorname{Lp}(a)$, but it remains unclear whether $L p(a)$ is a predictor independent of LDL-C or other prognostic factors. ${ }^{9}$ In addition, previous studies have not measured $\mathrm{Lp}$ (a) levels in the acute phase of ACS nor the prevalence of elevated Lp(a) levels in this specific high-risk setting. One of the main reasons has been the inability of traditional lipid-lowering agents, including statin and ezetimibe, to effectively lower Lp(a). ${ }^{1}$ Nevertheless, the more recent lipid-lowering monoclonal antibodies that inhibit proprotein convertase kexin/subtilisin 9 (PCSK9) have led to a 20-30\% reduction in Lp(a) levels, as well as a lowering of the incidence of CVD events after ACS, suggesting that Lp(a) could represent an appealing biomarker of residual CV risk amenable to therapy. ${ }^{10}$

Despite these encouraging results, the clinical relevance of $L p(a)$ for clinical purposes has been questioned and its measurement is not widely applied in clinical practice. More data are needed in the ACS setting to clarify whether measuring Lp(a) could be helpful beyond the currently recommended 
markers. Therefore, we evaluated the prevalence of elevated $\mathrm{Lp}$ (a) levels and investigated their prognostic value in a contemporary cohort of patients after ACS.

\section{Methods}

\section{Study Population}

The Special Programme University Medicine Acute Coronary Syndromes and Inflammation (SPUMACS) cohort consists of patients with a primary diagnosis of ACS referred for an angiography to one of four Swiss academic centers (Bern, Geneva, Lausanne, and Zürich, NCT01000701). ${ }^{11}$ For the analysis of plasma $\mathrm{Lp}(\mathrm{a})$ measurements we extracted data from patients enrolled between December 2009 and October 2012, as in our previous publications. ${ }^{11,12}$ Inclusion criteria comprised all females and males aged 18 years and older presenting within 5 days (preferably within $72 \mathrm{~h}$ ) after pain onset associated with either one of the following primary diagnoses: ST-elevation myocardial infarction (STEMI), non-ST-elevation myocardial infarction (NSTEMI) or unstable angina. Patients had to present symptoms compatible with angina pectoris (chest pain and dyspnea) and fulfill at least one of the following criteria: (i) persistent ST-segment elevation or depression, T-inversion, or dynamic electrocardiogram (ECG) changes, new left bundle branch block (LBBB); (ii) evidence of positive troponin by local laboratory reference values (with a rise and/or fall in serial troponin levels); (iii) known coronary artery disease, specified as status after myocardial infarction, coronary artery bypass grafting $(\mathrm{CABG})$, or percutaneous coronary intervention $(\mathrm{PCI})$ or newly documented, $\geq 50 \%$ stenosis of an epicardial coronary artery during initial catheterization. Exclusion criteria comprised severe physical disability, inability to comprehend the study or $<1$ year of life expectancy (for non-cardiac reasons). Follow-up was performed at 1 year (clinical visit) with events adjudicated by three independent experts using pre-specified adjudication forms.

\section{Familial hypercholesterolemia classification}

Based on a previous study, we used the validated Dutch Lipid Clinic Network algorithm for FH classification. ${ }^{13}$ In this algorithm, FH was considered possible when scoring 3-5 points, probable for 6-8 points and definite for $>8$ points. ${ }^{17}$ The diagnosis of possible FH required both an elevated LDL cholesterol $>4.9 \mathrm{mmol} / \mathrm{L}$ along with a family or personal history of premature atherosclerosis. Lipidlowering therapy included statin, fibrates, niacin, ezetimibe or resins.

This article is protected by copyright. All rights reserved. 


\section{Biomarker measurements}

Blood was drawn from the arterial sheath at coronary angiography (time-point 1, [T1]) and centrifuged at $2700 \times g$ for $10 \mathrm{~min}$ at room temperature to obtain plasma, and then frozen and stored in aliquots at $-80^{\circ} \mathrm{C}$. Aliquots were measured blinded to patients' data by means of numbered codes and then merged with the clinical dataset. Plasma Lp(a) levels were determined by means of particleenhanced immunonephelometry (Siemens BN ProSpec ${ }^{\mathrm{TM}}$ analyzer). The inter-assay coefficient of variation was $<3.9 \%$, the limit of detection (LoD) $2.5 \mathrm{mg} / \mathrm{l}$ and the limit of quantitation (LoQ) 100 $\mathrm{mg} / \mathrm{l}$. For cases below the LoD, we imputed the minimal value as $2.5 \mathrm{mg} / \mathrm{l}(\mathrm{N}=509$ patients). PCSK9 levels were measured in each patient using ethylenediaminetetraacetic acid (EDTA) plasma by colorimetric enzyme-linked immunosorbent assay from R\&D Systems (Minneapolis, MN, USA) according to the manufacturer's instructions. The minimal limit of detection was $0.625 \mathrm{ng} / \mathrm{mL}$, the mean intra- and inter-assay coefficient of variation was at the accepted threshold of $<8 \%$. The cut-off of $30 \mathrm{mg} / \mathrm{dL}$ for this essay corresponds to the $75^{\text {th }}$ percentile in male Caucasian reference population. High-sensitive cardiac troponin $\mathrm{T}$ (hs-TnT), N-terminal-pro B-type natriuretic peptide (NT-proBNP) and high-sensitive C-reactive protein (hs-CRP) were measured in one serum aliquot per patient at the Zürich Core Laboratory using a electrochemiluminescence immunoassay on a cobas e $602^{\circledR}$ reader (all Roche Diagnostics, Mannheim, Germany), with assay characteristics as reported by the manufacturer. ${ }^{14}$

\section{Study endpoints}

The primary endpoint was a composite of major adverse cardiovascular events (MACE) defined as cardiac death, myocardial infarction or stroke. The secondary clinical endpoints comprised all-cause death, cardiac death, myocardial infarction, cerebrovascular events (ischemic or hemorrhagic stroke including transient ischemic attack) and clinically indicated coronary revascularization. Clinical endpoints were adjudicated by a panel of independent experts (three certified cardiologists) blinded to the results of $\mathrm{Lp}(\mathrm{a})$. Participants were first followed up at 30 days by telephone by a trained study nurse and were then asked to attended a clinical visit at one-year post-ACS. If patients were unable to attend the clinic visit, follow-up was performed using either of the following alternatives, listed by order of preference: (i) phone call, (ii) postal mail or email, (iii) through family members, or (iv) via the primary care physician or cardiologist.

\section{Statistical methods}

The data were expressed as medians \pm interquartile range for continuous variables and as numbers and percentages for categorical variables. The correlation between $\mathrm{Lp}(\mathrm{a})$ levels and other biomarkers was evaluated by a nonparametric test (Spearman rank correlation). Using logistic regression model 
adjusted for previously tested confounding variables, ${ }^{15}$ we evaluated the odds ratios (OR) and the 95\% confidence intervals (95\% CI) of the association between $\mathrm{Lp}(\mathrm{a})$ values at time of the angiography and the achievement of LDL-C targets one year after ACS. Continuous Lp(a) levels were categorized into tertiles to assess their association with clinical outcomes. ${ }^{18} \mathrm{We}$ also classified patients into two groups, according to whether their $\mathrm{Lp}$ (a) levels were elevated ( $\geq 30 \mathrm{mg} / \mathrm{dL}$ ) or normal $(<30 \mathrm{mg} / \mathrm{dL})$. The time-to-first event or composite events were analyzed censoring patients at 365 days, death, or last valid contact date. The univariable association of $\mathrm{Lp}(\mathrm{a})$ tertiles with all-cause death and secondary clinical outcomes was evaluated using Cox proportional hazards models and expressed with hazard ratios (HRs) and 95\% confidence intervals (CI). We examined the proportionality of hazards using graphical methods and Schoenfeld residual tests. To increase statistical power, we additionally considered continuous $L p(a)$ concentrations, estimating the effect on clinical outcomes per 1 standard deviation (SD) increase. Effect estimates were presented as HR and 95\% CI. In the multivariable model, we adjusted for traditional CV risk factors (age, sex, smoking, diabetes, hypertension, LDL-C, high-density lipoprotein cholesterol [HDL-C], triglycerides and body mass index). All hypothesis tests were two-sided and the significance level wa set at 5\%. Statistical analyses were performed using STATA software ${ }^{\circledR}$ (Version 15, STATA Corp, College Station, TX, USA). Reporting of the study conforms to the STROBE statement along with references to the STROBE statement and the broader EQUATOR guidelines. ${ }^{16}$

\section{Results}

Among the 2168 patients recruited, 1711 had available data on Lp(a) plasma levels at baseline (T1), Figure 1 depicts the distribution of $\mathrm{Lp}$ (a) levels, the range was between $2.5 \mathrm{mg} / \mathrm{dL}$ to $132 \mathrm{mg} / \mathrm{dL}$ with a median value of $6 \mathrm{mg} / \mathrm{dL}$ and a mean value of $14.2 \mathrm{mg} / \mathrm{dL}$. A total of 92 patients (5.4\%) had $\mathrm{Lp}(\mathrm{a})$ plasma levels $\geq 50 \mathrm{mg} / \mathrm{dL}$ and 276 patients $(23.0 \%)$ has plasma level $\geq 30 \mathrm{mg} / \mathrm{dL}$. Patients with elevated Lp(a) values were more likely to be female, and have higher levels of total cholesterol, LDL$\mathrm{C}$ and HDL-C PCSK9 (Table 1). Mean age was $63.9 \pm 12.6$ years, $15.2 \%$ had a history of MI, 31.3\% were already on statin treatment and $2.3 \%$ on other lipid-lowering agents. The percentage of women significantly increased also across $\mathrm{Lp}$ (a) tertiles, passing from $17.0 \%$ in the lowest tertile to $25.2 \%$ in the highest tertile $(\mathrm{P}=0.003)$.

Baseline $\mathrm{Lp}(\mathrm{a})$ values were significantly and positively correlated with total cholesterol, LDL-C and HDL-C values, and negatively with triglycerides at one-year follow-up (Table 2). No correlation was found between $\mathrm{Lp}(\mathrm{s})$ values and cardiac biomarkers (HsTnT, CK, NT-pro BNP) or inflammation (hs $\mathrm{CRP}$ ). In addition, no significant differences in $\mathrm{Lp}(\mathrm{a})$ were observed according to the duration of chest

This article is protected by copyright. All rights reserved. 
pain prior to blood draw. Discharge therapies were similar for both elevated and normal Lp(a) groups (Supplemental Table 1).

At one-year follow-up, compliance to statin therapy was comparable between both groups (95\% for patients with $\mathrm{Lp}$ (a) levels $\geq 30 \mathrm{mg} / \mathrm{dL}$ and $93 \%$ for $\mathrm{Lp}$ (a) levels $<30 \mathrm{mg} / \mathrm{dL} ; \mathrm{P}=0.42$, Supplemental Table 2), and the use of non-statin lipid-lowering agents was uncommon (5\% vs. \%, respectively; $\mathrm{P}=$ 0.55). Regarding the subgroup of patients with available data for LDL-C at one year (Supplemental Table 2), patients with elevated Lp(a) had significantly higher mean LDL-C levels one-year after ACS compared to normal $\mathrm{Lp}$ (a) values $(2.4 \pm 0.7 \mathrm{mmol} / \mathrm{l}$ vs. $2.2 \pm 0.9 \mathrm{mmol} / \mathrm{l}, \mathrm{P}=0.003)$. Furthermore, a significantly lower proportion of patients with elevated $\mathrm{Lp}$ (a) values reached the LDL-C target of < $1.8 \mathrm{mmol} / \mathrm{l}(24 \%$ vs. $38 \%, \mathrm{P}=0.003)$. In the multivariate variables adjusting for potential confounding factors, high Lp(a) levels at time of ACS were associated with failure to reach LDL-C targets one year after ACS (Table 3, HR 1.71. 95\% CI 1.13-2.58, $\mathrm{P}=0.011$ ).

The rate of MACE was similar between both $\mathrm{Lp}$ (a) groups, as were the clinical outcomes in crude and adjusted Cox regression models (Table 4). MACE rates were $8.3 \%$ for the group with elevated Lp(a) levels vs. $8.6 \%$ for patients with normal Lp(a) (HR 1.05, 95\% CI 0.64-1.73, P =0.84). Equally, HRs for highest vs. lowest $\mathrm{Lp}(\mathrm{a})$ tertiles did not differ significantly for any of the clinical outcomes, whether taken separately or as a composite endpoint (Table 5, Figure 2) Results were also similar when considering $L p(a)$ as a continuous standardized value (HR 0.98, 95\% CI 0.82-1.19 for each increase in SD). In sensitivity analyses, no significant interactions were found relative to the presence FH (Supplemental Table 3) and HRs were similar for nonfatal outcomes when using all-cause death as a competitive risk in the model (Supplemental Table 4).

\section{Discussion}

This large prospective cohort study of patients with ACS adds new evidence to the prognostic role of circulating Lp(a) plasma levels in patients with ACS: (i) the prevalence of elevated Lp(a) plasma levels at initial presentation is about $16 \%$ and an important amount of patients had values below the limit of quantification; (ii) higher Lp(a) plasma levels were associated with higher LDL-C values, but not with inflammation or cardiac injury markers; (iii) $L$ (a) plasma levels obtained at initial presentation were not significantly associated with all-cause mortality, cardiac mortality, recurrent myocardial infarction or stroke at 1 year; (iv) patients with elevated Lp(a) plasma levels at initial presentation were less likely to reach the recommended target of LDL-C $<1.8 \mathrm{mmol}(<70 \mathrm{mg} / \mathrm{dL})$ at 1 year.

This article is protected by copyright. All rights reserved. 
Our study is one of the largest to evaluate Lp(a) plasma levels specifically in ACS patients undergoing coronary angiography and, in most cases, primary percutaneous coronary intervention. Surprisingly, our findings indicate that assessing Lp(a) plasma levels in the acute ACS setting is likely to be devoid of clinical utility in terms of risk stratification. Compared to a primary prevention setting, the ACS population of the present cohort is characterized by very high use of statin, aspirin and P2Y12 inhibitors at discharge and at one year, which could potentially counteract the prothrombotic and proatherogenic properties of $\mathrm{Lp}(\mathrm{a})$. Furthermore, our data suggest that the acute condition of ACS might represent an pre-analytical factor able to substantially affect $L p(a)$ levels. However, we did not find any significant correlation between the levels of $L p(a)$ and the amount of inflammation or myocardial injury. Current evidence is controversial regarding the prognostic value of $\operatorname{Lp}(\mathrm{a})$ in secondary prevention and for patients on statin. In the Rosuvastatin Versus Atorvastatin (SATURN) trial, baseline and follow-up Lp(a) levels were not associated with changes in percent atheroma volume as measured with ultrasound. ${ }^{17}$ LDL-C decreased from $114 \mathrm{mg} / \mathrm{dL}$ to $60 \mathrm{mg} / \mathrm{dL}$, while $\mathrm{Lp}(\mathrm{a})$ remained unchanged $(17.4 \mathrm{mg} / \mathrm{dL}$ and $16.5 \mathrm{mg} / \mathrm{dL}$, respectively) with statin therapy. The cut-off of 50 $\mathrm{mg} / \mathrm{dl}$ for $\mathrm{Lp}$ (a) was neither protective nor a risk factor for disease progression. ${ }^{17}$ In a sub-analysis of the Study of Dalcetrapib in Patients Hospitalized for an Acute Coronary Syndrome (dalOUTCOMES), no association was found between $\mathrm{Lp}(\mathrm{a})$ concentrations and major adverse outcomes including 4139 patients treated with statins: for a doubling of the dose of $\mathrm{Lp}(\mathrm{a})$, the level of risk for CVD was stagnant (HR 1.01, 95\% CI 0.96-1.06, $\mathrm{P}=0.66) .{ }^{18}$ Similar results were also reported in 3 different pooled studies with 6708 subjects known for coronary artery disease: the odds ratios (OR) were 1.03 (95\% CI 0.96-1.11) for each increase in log-transformed standard deviation of $\mathrm{Lp}(\mathrm{a})$ or by quintile (highest vs. lowest OR 1.05, 95\% CI 0.83-1.34). ${ }^{9}$ Some other data suggested that the risk associated with $\mathrm{Lp}$ (a) in patients with premature ACS was predominantly observed in those with concomitant elevated LDL-C levels, and not for patients with low LDL-C. ${ }^{19}$ Recently, an individual patient-data meta-analysis of 29,069 patients from statin outcome trials suggested that baseline $\mathrm{Lp}(\mathrm{a})$ levels, as well as $\mathrm{Lp}(\mathrm{a})$ values on statin therapy were both associated with CVD events, especially for values higher than $50 \mathrm{mg} / \mathrm{dL}$ after adjustment for confounding factors. ${ }^{20}$ Therefore, the association between $\mathrm{Lp}(\mathrm{a})$ and major adverse cardiovascular events in a population already treated with statin, especially after ACS, is not consistent across literature. ${ }^{9,}{ }^{18}$ Along these lines, the association of Lp(a) with LDL-C is, however, well established and $\mathrm{Lp}(\mathrm{a})$ is also considered as a marker for the diagnosis of FH. ${ }^{1,5}$ Finally, we also observed that Lp(a) levels were higher in women, as recently reported in the FOURIER trial. ${ }^{21}$

Defining the Lp(a) cut-off for populations at risk is a source of controversy. ${ }^{1}$ The cut-off of $50 \mathrm{mg} / \mathrm{dL}$ was mainly based on the fact that $20 \%$ of subjects from the general population have Lp(a) levels above $50 \mathrm{mg} / \mathrm{dL} .{ }^{5}$ Moreover, this threshold is assay-specific, as some studies have shown a significant risk increase already at $\mathrm{Lp}($ a) levels above $30 \mathrm{mg} / \mathrm{dL}$, as demonstrated for the assay used in this

This article is protected by copyright. All rights reserved. 
study. ${ }^{1}$ No randomized controlled trial has shown a positive correlation between the reduction of Lp(a) and CVD events. Statin therapy has not shown to significantly impact Lp(a) levels. ${ }^{1}$ Niacin was also evaluated for reducing $\mathrm{Lp}$ (a) levels, but has since been withdrawn from the market following evidence of therapeutic futility. ${ }^{22}$ More recently, trials testing monoclonal antibodies directed against PCSK9 have reported a significant $25-30 \%$ decrease in $\mathrm{Lp}$ (a) values, as shown in a pooled analysis from 1359 patients. ${ }^{10}$ The reduction of $L p(a)$ was, however, significantly correlated with the percentage reduction of LDL-C and currently no evidence suggests that isolated reduction of Lp(a) could improve outcomes. ${ }^{23}$ Recently, treatment with antisense oligonucleotides targeting Apo(a) has shown that it can lower Lp(a) levels by up to $80 \%$ in individuals with elevated Lp(a). ${ }^{24}$ A clinical study with CVD outcomes is now required to evaluate the specific impact of reducing Lp(a) alone. Along these lines, the sub-analysis of the Further Cardiovascular Outcomes Research with PCSK9 Inhibition in Subjects with Elevated Risk (FOURIER) and the Evaluation of Cardiovascular Outcomes After an Acute Coronary Syndrome During Treatment With Alirocumab (ODYSSEY) data would clarify whether achieving $\mathrm{Lp}$ (a) target values $<50 \mathrm{mg} / \mathrm{dL}$ in secondary prevention would improve prognosis or change the effect of PCSK9 inhibition on clinical outcomes.

\section{Strengths and limitations}

The major strength of this study is that it consists of a large cohort of patients with ACS with complete one-year follow-up data and characterized by the measurement of $L p(a)$ values at the time of angiography. The study population was medically well controlled, as illustrated by the extensive use of recommended treatments including statin and antiplatelet therapy, thereby offering a real-world setting for the assessment of biomarkers. However, we cannot exclude that our follow-up period of one year was not sufficient to detect a possible association at mid- or long-term. The recently published sub-analysis from the FOURIER study including 25,096 high-risk stable patients reported an association between $\mathrm{Lp}(\mathrm{a})$ and major adverse cardiovascular events with a median follow-up of 3 years, and this independently of LDL-C. ${ }^{21}$ Although our data were observational and not randomized, we also took into consideration key confounding factors, such as inflammation and cardiac biomarkers, as well as the GRACE score. Other limitations include potential underpowered statistical analyses for the elevated $\mathrm{Lp}(\mathrm{a})$ strata $(\geq 30 \mathrm{mg} / \mathrm{dL})$, which is the reason why we did not use a more stringent cut-off of $\geq 50 \mathrm{mg} / \mathrm{dL}$. However, analyses evaluating tertiles or standardized continuous $\mathrm{Lp}$ (a) corroborated our observations. Although we did not compare $\mathrm{Lp}(\mathrm{a})$ values measured at baseline with sample values collected during follow-up, our data do not suggest that $\operatorname{Lp}(\mathrm{a})$ levels were associated with the amount of inflammation or cardiac injury; rather, their distribution tends towards lower values than usually described in the high-risk population. Moreover, ACS causes a rapid decline in LDL-C levels, making their interpretation $24 \mathrm{~h}$ post-MI unreliable for the steady-state

This article is protected by copyright. All rights reserved. 
level. ${ }^{25}$ Finally, as with all biomarker studies, pre-analytical (long-term stability of $\mathrm{Lp}$ (a) at $-80^{\circ} \mathrm{C}$ is poorly known) as well as analytical aspects may have affected our findings. As samples were stored for 4-5 years prior to analysis, degradation of $\mathrm{Lp}$ (a) may have occurred.

\section{Conclusions}

Although $\mathrm{Lp}(\mathrm{a})$ is associated with proatherogenic and prothrombotic properties, the present study demonstrated that elevated $\mathrm{Lp}$ (a) values at time of angiography were not associated with worse clinical outcomes at one year in medically well controlled patients. However, measurement of Lp(a) might be useful to identify patients who would not be on LDL-C targets one year after ACS independently of other lipid particles.

\section{Funding}

The work was supported by the Swiss National Science Foundation (SPUM 33CM30-124112 and SPUM 33CM30-140 336, Inflammation and acute coronary syndromes (ACS)-Novel strategies for prevention and clinical management, and 32473B_163271, Long-term Benefit of the Multi-Center, Multi-Dimensional Secondary Prevention Program in Patients With Acute Coronary Syndromes). B.G.'s research is supported by grants from the Geneva University Hospitals, Swiss Heart Foundation, de Reuter Foundation, Gerbex-Bourget Foundation, Gustave-Prevot and Arthemis Foundation. N.R.'s research is supported by grants from the Swiss National Science Foundation (SNSF 320030-150025). R.A. and N.R.'s research on cardiovascular prevention is supported by grants from the Swiss Heart Foundation. The SPUM consortium was also supported by Roche Diagnostics, Eli Lilly, AstraZeneca, Medtronic, Merck Sharpe and Dome (MSD), Sanofi-Aventis; St. Jude Medical as well as the Zurich Heart House - Foundation for Cardiovascular Research, Zurich, Switzerland. None of the funding institutions had any role in the design and conduct of the study, collection, management, analysis and interpretation of the data, as well as preparation, review, or approval of the manuscript.

\section{Acknowledgements}

We acknowledge the work of the clinical event committee for SPUM ACS: Matthias Pfisterer, MD, University of Basel (chair), Tiziano Moccetti, MD, CardioCentro Lugano, Lukas Kappenberger, MD, Lausanne University, Switzerland. We thank the local study nurses, the core lab technicians, the central data monitors, the electronic data conducting system (2mt GmbH Ulm, Jürgen Nagler-Ihlein, Torsten Illmann), the research coordinator Lambertus J. van Tits, PhD and the members of the local 
catheter teams for their invaluable work. Special gratitude is expressed to Aliki Buhayer (Prism Scientific Sàrl) for medical writing support.

\section{Disclosures}

T.F.L reports receiving research grants to the institution from Abbot, Biosensors, Biotronik, Boston Scientific, Daichi Sankyo, Eli Lilly and Medtronic, and consultant payments from Amgen, AstraZeneca, Boehringer Ingelheim, Bayer, Merck, and Pfizer, MSD, Roche, and Servier. C.M.M. reports receiving grants from MSD, AstraZeneca, and Roche, and having patents from Mabimmune, CH. S.W. reports receiving research contracts to the institution from Abbott, Biotronik, Boston Scientific, Biosensors, Cordis, Medtronic, St Jude Medical, and speaker fees from Abbott, Biotronik, Boston Scientific, Biosensors, Medtronic, Eli Lilly, and AstraZeneca. Other authors did not report disclosures.

\section{References}

1. Gencer B, Kronenberg F, Stroes ES and Mach F. Lipoprotein(a): the revenant. European heart journal. 2017;38:1553-1560.

2. Schmidt K, Noureen A, Kronenberg F and Utermann G. Structure, function, and genetics of lipoprotein (a). Journal of lipid research. 2016;57:1339-59.

3. Erqou S, Kaptoge S, Perry PL, Di Angelantonio E, Thompson A, White IR, Marcovina SM, Collins R, Thompson SG and Danesh J. Lipoprotein(a) concentration and the risk of coronary heart disease, stroke, and nonvascular mortality. Jama. 2009;302:412-23.

4. Kamstrup PR, Tybjaerg-Hansen A, Steffensen R and Nordestgaard BG. Genetically elevated lipoprotein(a) and increased risk of myocardial infarction. Jama. 2009;301:2331-9.

5. Nordestgaard BG, Chapman MJ, Ray K, Boren J, Andreotti F, Watts GF, Ginsberg H, Amarenco P, Catapano A, Descamps OS, Fisher E, Kovanen PT, Kuivenhoven JA, Lesnik P, Masana L, Reiner Z, Taskinen MR, Tokgozoglu L and Tybjaerg-Hansen A. Lipoprotein(a) as a cardiovascular risk factor: current status. European heart journal. 2010;31:2844-53.

6. Verbeek R, Boekholdt SM, Stoekenbroek RM, Hovingh GK, Witztum JL, Wareham NJ, Sandhu MS, Khaw KT and Tsimikas S. Population and assay thresholds for the predictive value of lipoprotein

(a) for coronary artery disease: the EPIC-Norfolk Prospective Population Study. Journal of lipid research. 2016;57:697-705.

7. Catapano AL, Graham I, De Backer G, Wiklund O, Chapman MJ, Drexel H, Hoes AW, Jennings CS, Landmesser U, Pedersen TR, Reiner Z, Riccardi G, Taskinen MR, Tokgozoglu L, Verschuren WMM, Vlachopoulos C, Wood DA, Zamorano JL and Cooney MT. 2016 ESC/EAS Guidelines for the Management of Dyslipidaemias. European heart journal. 2016;37:2999-3058.

8. Nanchen D, Gencer B, Muller O, Auer R, Aghlmandi S, Heg D, Klingenberg R, Raber L, Carballo D, Carballo S, Matter CM, Luscher TF, Windecker S, Mach F and Rodondi N. Prognosis of Patients With Familial Hypercholesterolemia After Acute Coronary Syndromes. Circulation. 2016;134:698709.

9. O'Donoghue ML, Morrow DA, Tsimikas S, Sloan S, Ren AF, Hoffman EB, Desai NR, Solomon SD, Domanski M, Arai K, Chiuve SE, Cannon CP, Sacks FM and Sabatine MS. Lipoprotein(a) for risk assessment in patients with established coronary artery disease. Journal of the American College of Cardiology. 2014;63:520-7.

This article is protected by copyright. All rights reserved. 
10. Raal FJ, Giugliano RP, Sabatine MS, Koren MJ, Langslet G, Bays H, Blom D, Eriksson M, Dent R, Wasserman SM, Huang F, Xue A, Albizem M, Scott R and Stein EA. Reduction in lipoprotein(a) with PCSK9 monoclonal antibody evolocumab (AMG 145): a pooled analysis of more than 1,300 patients in 4 phase II trials. Journal of the American College of Cardiology. 2014;63:1278-1288.

11. Gencer B, Montecucco F, Nanchen D, Carbone F, Klingenberg R, Vuilleumier N, Aghlmandi S, Heg D, Raber L, Auer R, Juni P, Windecker S, Luscher TF, Matter CM, Rodondi N and Mach F.

Prognostic value of PCSK9 levels in patients with acute coronary syndromes. European heart journal. 2016;37:546-53.

12. Klingenberg R, Aghlmandi S, Liebetrau C, Raber L, Gencer B, Nanchen D, Carballo D, Akhmedov A, Montecucco F, Zoller S, Brokopp C, Heg D, Juni P, Marti Soler H, Marques-Vidal PM, Vollenweider P, Dorr O, Rodondi N, Mach F, Windecker S, Landmesser U, von Eckardstein A, Hamm $\mathrm{CW}$, Matter CM and Luscher TF. Cysteine-rich angiogenic inducer 61 (Cyr61): a novel soluble biomarker of acute myocardial injury improves risk stratification after acute coronary syndromes. European heart journal. 2017;38:3493-3502.

13. Nanchen D, Gencer B, Auer R, Raber L, Stefanini GG, Klingenberg R, Schmied CM, Cornuz J, Muller O, Vogt P, Juni P, Matter CM, Windecker S, Luscher TF, Mach F and Rodondi N. Prevalence and management of familial hypercholesterolaemia in patients with acute coronary syndromes. European heart journal. 2015;36:2438-45.

14. Klingenberg R, Aghlmandi S, Raber L, Gencer B, Nanchen D, Heg D, Carballo S, Rodondi N, Mach F, Windecker S, Juni P, von Eckardstein A, Matter CM and Luscher TF. Improved risk stratification of patients with acute coronary syndromes using a combination of hsTnT, NT-proBNP and hsCRP with the GRACE score. European heart journal Acute cardiovascular care. 2018;7:129-138. 15. Gencer B, Auer R, Nanchen D, Raber L, Klingenberg R, Carballo D, Blum M, Vogt P, Carballo S, Meyer P, Matter CM, Windecker S, Luscher TF, Mach F and Rodondi N. Expected impact of applying new 2013 AHA/ACC cholesterol guidelines criteria on the recommended lipid target achievement after acute coronary syndromes. Atherosclerosis. 2015;239:118-24.

16. Simera I, Moher D, Hoey J, Schulz KF and Altman DG. A catalogue of reporting guidelines for health research. European journal of clinical investigation. 2010;40:35-53.

17. Puri R, Ballantyne CM, Hoogeveen RC, Shao M, Barter P, Libby P, Chapman MJ, Erbel R, Arsenault BJ, Raichlen JS, Nissen SE and Nicholls SJ. Lipoprotein(a) and coronary atheroma progression rates during long-term high-intensity statin therapy: Insights from SATURN. Atherosclerosis. 2017;263:137-144.

18. Schwartz GG, Ballantyne CM, Barter PJ, Kallend D, Leiter LA, Leitersdorf E, McMurray JJV, Nicholls SJ, Olsson AG, Shah PK, Tardif JC and Kittelson J. Association of Lipoprotein(a) With Risk of Recurrent Ischemic Events Following Acute Coronary Syndrome: Analysis of the dal-Outcomes Randomized Clinical Trial. JAMA cardiology. 2018;3:164-168.

19. Afshar M, Pilote L, Dufresne L, Engert JC and Thanassoulis G. Lipoprotein(a) Interactions With Low-Density Lipoprotein Cholesterol and Other Cardiovascular Risk Factors in Premature Acute Coronary Syndrome (ACS). J Am Heart Assoc. 2016;5.

20. Willeit P, Ridker PM, Nestel PJ, Simes J, Tonkin AM, Pedersen TR, Schwartz GG, Olsson AG, Colhoun HM, Kronenberg F, Drechsler C, Wanner C, Mora S, Lesogor A and Tsimikas S. Baseline and on-statin treatment lipoprotein(a) levels for prediction of cardiovascular events: individual patientdata meta-analysis of statin outcome trials. Lancet. 2018;392:1311-1320.

21. O'Donoghue ML, Fazio S, Giugliano RP, Stroes ESG, Kanevsky E, Gouni-Berthold I, Im K, Lira Pineda A, Wasserman SM, Ceska R, Ezhov MV, Jukema JW, Jensen HK, Tokgozoglu SL, Mach F, Huber K, Sever PS, Keech AC, Pedersen TR and Sabatine MS. Lipoprotein(a), PCSK9 Inhibition and Cardiovascular Risk: Insights from the FOURIER Trial. Circulation. 2018.

22. Landray MJ, Haynes R and Armitage J. Niacin for reduction of cardiovascular risk. The New England journal of medicine. 2014;371:1943-4.

23. Raal FJ, Giugliano RP, Sabatine MS, Koren MJ, Blom D, Seidah NG, Honarpour N, Lira A, Xue A, Chiruvolu P, Jackson S, Di M, Peach M, Somaratne R, Wasserman SM, Scott R and Stein EA. PCSK9

This article is protected by copyright. All rights reserved. 
inhibition-mediated reduction in Lp(a) with evolocumab: an analysis of 10 clinical trials and the LDL receptor's role. Journal of lipid research. 2016;57:1086-96.

24. Tsimikas S, Viney NJ, Hughes SG, Singleton W, Graham MJ, Baker BF, Burkey JL, Yang Q, Marcovina SM, Geary RS, Crooke RM and Witztum JL. Antisense therapy targeting apolipoprotein(a): a randomised, double-blind, placebo-controlled phase 1 study. Lancet. 2015;386:1472-83. 25. Wattanasuwan N, Khan IA, Gowda RM, Vasavada BC and Sacchi TJ. Effect of acute myocardial infarction on cholesterol ratios. Chest. 2001;120:1196-9.

This article is protected by copyright. All rights reserved. 
TABLES

\begin{tabular}{|c|c|c|c|}
\hline \multicolumn{4}{|c|}{ Table 1. Baseline characteristics of 1711 patients with ACS } \\
\hline & $\mathrm{Lp}(\mathrm{a}) \geq 30 \mathrm{mg} / \mathrm{dL}$ & Lp(a) $<30 \mathrm{mg} / \mathrm{dL}$ & p value \\
\hline & $(n=276)$ & $(n=1435)$ & \\
\hline \multicolumn{4}{|l|}{ Demographics } \\
\hline Age, yr. & $64.1 \pm 11.7$ & $63.8 \pm 12.7$ & 0.75 \\
\hline Woman, n (\%) & $36(31.2)$ & $284(19.8)$ & $<0.001$ \\
\hline BMI, $\mathrm{kg} / \mathrm{m}^{2}$ & $26.6 \pm 5.0$ & $27.2 \pm 4.3$ & 0.03 \\
\hline Hypertension, no. (\%) & $159(57.6)$ & $595(41.5)$ & 0.78 \\
\hline Diabetes, no. (\%) & $44(15.9)$ & $279(19.4)$ & 0.17 \\
\hline FH classification, no $(\%)$ & & & 0.61 \\
\hline No FH & $218(80.8)$ & $1146(81.4)$ & \\
\hline Possible or probable & $54(19.9)$ & $262(18.6)$ & \\
\hline Current Smoking, no. (\%) & $98(35.8)$ & $580(41.3)$ & 0.08 \\
\hline Use of statin, no. (\%) & $97(35.3)$ & $435(30.5)$ & 0.12 \\
\hline History of MI, no (\%) & $39(14.1)$ & $221(15.4)$ & 0.59 \\
\hline History of malignancy, no (\%) & $27(9.8)$ & $106(7.4)$ & 0.17 \\
\hline Family history CAD, no (\%) & $79(29.2)$ & $349(24.8)$ & 0.13 \\
\hline \multicolumn{4}{|l|}{ Clinical presentation } \\
\hline $\mathrm{ACS}^{\prime}$ type & & & 0.91 \\
\hline STEMI, no (\%) & $142(51.5)$ & $722(50.3)$ & \\
\hline NSTEMI, no (\%) & $124(44.9)$ & $655(45.6)$ & \\
\hline Unstable angina & $10(3.6)$ & $58(4.0)$ & \\
\hline Killip classification & & & 0.08 \\
\hline $\mathrm{I}$, no. $(\%)$ & $226(81.9)$ & $1247(86.9)$ & \\
\hline II, no. $(\%)$ & $36(13.0)$ & $128(8.9)$ & \\
\hline III, no. (\%) & $8(2.9)$ & $24(1.7)$ & \\
\hline IV, no. $(\%)$ & $6(2.2)$ & $36(2.5)$ & \\
\hline $\mathrm{SBP}, \mathrm{mmHg}$ & $131.0 \pm 23.7$ & $129.8 \pm 23.0$ & 0.40 \\
\hline DBP $\mathrm{mmHg}$ & $75.0 \pm 13.8$ & $74.7 \pm 14.9$ & 0.72 \\
\hline Revascularization (PCI or CABG) & $255(92.4)$ & $1347(93.9)$ & 0.36 \\
\hline \multicolumn{4}{|l|}{ Biochemical values } \\
\hline Cholesterol (mmol/l) & $5.1 \pm 1.3$ & $4.9 \pm 1.3$ & 0.01 \\
\hline LDL-C (mmol/l) & $3.7 \pm 1.1$ & $3.3 \pm 1.1$ & $<0.001$ \\
\hline Triglycerides (mmol? 1$)$ & $1.1 \pm 0.8$ & $1.4 \pm 1.31$ & 0.001 \\
\hline HDL-C (mmol/l) & $1.3 \pm 0.2$ & $1.2 \pm 0.4$ & $<0.001$ \\
\hline PCSK9 (ng/ml) & $341.3 \pm 147.1$ & $329.3 \pm 145.9$ & 0.22 \\
\hline $\mathrm{CRP}(\mathrm{mg} / \mathrm{L})$ & $9.5 \pm 1.6$ & $11.1 \pm 0.7$ & 0.35 \\
\hline Creatinine (mg/dl) & $81.3 \pm 27.1$ & $84.3 \pm 46.3$ & 0.28 \\
\hline Glucose $(\mathrm{mmol} / \mathrm{l})$ & $6.9 \pm 2.2$ & $7.1 \pm 2.8$ & 0.48 \\
\hline \multicolumn{4}{|c|}{$\begin{array}{l}\text { Data are expressed as mean } \pm \text { standard deviation or number (no.) and percentages (\%). Two-tailed Fisher's exact tests for } \\
\text { dichotomous variables, larger Chi-squared test for }{ }^{+} \text {T-Test or Mann-Whitney-U tests for continuous variables, were } \\
\text { utilized as appropriate. Abbreviations: ACS, acute coronary syndromes; BMI, body mass index; CABG, coronary artery } \\
\text { bypass grafting; CAD, coronary artery disease; CRP, C-reactive protein; DBP, diastolic blood pressure; FH, familial } \\
\text { hypercholesterolemia; HDL-C, high-density lipoprotein cholesterol; LDL-C, low-density lipoprotein cholesterol; MI, } \\
\text { myocardial infarction; NSTEMI, Non ST-elevation myocardial infarction; PCI, percutaneous coronary intervention; } \\
\text { PCSK9, proprotein convertase subtilisin kexin 9; PVD, peripheral vascular disease; SBP, systolic blood pressure; STEMI, } \\
\text { ST-elevation myocardial infarction }\end{array}$} \\
\hline
\end{tabular}

This article is protected by copyright. All rights reserved. 
Table 2 Correlations between $L p(a)$ and other biomarkers

\begin{tabular}{|l|c|c|}
\hline Biomarkers & Rho \# & P-value \\
\hline LDL-C $(\mathrm{mmol} / \mathrm{l})$ & 0.105 & $<\mathbf{0 . 0 0 1}$ \\
\hline HDL-C $(\mathrm{mmol} / \mathrm{l})$ & 0.116 & $<\mathbf{0 . 0 0 1}$ \\
\hline Triglycerides $(\mathrm{mmol} / \mathrm{l})$ & -0.125 & $<\mathbf{0 . 0 0 1}$ \\
\hline PCSK9 $(\mathrm{ng} / \mathrm{ml})$ & 0.027 & 0.259 \\
\hline Creatinine $(\mathrm{mg} / \mathrm{dl})$ & -0.013 & 0.600 \\
\hline hs-CRP $(\mathrm{mg} / \mathrm{l})$ & -0.024 & 0.359 \\
\hline Hs Troponin $(\mu \mathrm{g} / \mathrm{l})$ & -0.002 & 0.938 \\
\hline CK $(\mathrm{U} / \mathrm{l})$ & -0.004 & 0.889 \\
\hline NT-pro BNP $(\mathrm{ng} / \mathrm{l})$ & 0.020 & 0.429 \\
\hline Glucose $(\mathrm{mmol} / \mathrm{l})$ & -0.031 & 0.235 \\
\hline $\begin{array}{l}\text { \# Spearman's rank correlation rho for continuous variables; Rho=1 denotes perfect } \\
\text { positive correlation, rho=-1 denotes perfect negative correlation and Rho=0 } \\
\text { absence of correlation. Abbreviations: CK, creatinine kinase; hs-CRP, high- } \\
\text { sensitive C-reactive protein; HDL-C, high-density lipoprotein cholesterol; LDL-C, } \\
\text { low-density lipoprotein cholesterol; NT-pro BNP, N-terminal-pro B-type natriuretic } \\
\text { peptide; PCSK9 proprotein convertase subtilisin kexin 9. }\end{array}$ \\
\hline \multicolumn{2}{|l|}{} \\
\hline
\end{tabular}

This article is protected by copyright. All rights reserved. 
Table 3 Clinical Associated Factors With Failure to Achieve LDL-C Targets One Year After ACS

\begin{tabular}{|l|c|c|}
\hline & Odds Ratios (95\% CI ) & P-value \\
\hline Lp(a) Tertile & $1($ Ref $)$ & \\
\hline \multicolumn{1}{|c|}{$1^{\text {st }}$ Tertile } & $1.03(0.70-1.53)$ & 0.864 \\
\hline $2^{\text {nd }}$ Tertile & $1.71(1.13-2.58)$ & 0.011 \\
\hline $3^{\text {rd }}$ Tertile & $0.98(0.97-1.00)$ & 0.021 \\
\hline Age (per year increase) & $1.33(0.84-2.11)$ & 0.218 \\
\hline Sex (women) & $0.97(0.93-1.01)$ & 0.118 \\
\hline Body mass index (per unit increase) & $1.35(0.87-2.09)$ & $<0.183$ \\
\hline History of diabetes & $0.06(0.01-0.3)$ & $<0.001$ \\
\hline Use of statin at one year & $2.21(1.85-2.65)$ & 0.051 \\
\hline LDL-C (per mmol/l increase) & $1.68(1.00-2.85)$ & 0.016 \\
\hline HDL-C (per mmol/l increase) & $1.16(1.03-1.31)$ & 0.047 \\
\hline Triglycerides (per mmol/l increase) & $0.68(0.46-1.00)$ & \\
\hline Attendance to cardiac rehabilitation & & \\
\hline $\begin{array}{l}\text { Abbreviations: ACS, acute coronary syndromes; CI, confidence intervals; HDL-C, high-density lipoprotein cholesterol; LDL-C, low- } \\
\text { density lipoprotein cholesterol; Lp(a), Lipoprotein (a); }\end{array}$ & \\
\hline
\end{tabular}

This article is protected by copyright. All rights reserved. 


\begin{tabular}{|c|c|c|c|c|}
\hline \multicolumn{5}{|c|}{ Table 4 Association between elevated $L p(a)$ values and clinical outcomes at one year } \\
\hline \multirow{2}{*}{$\begin{array}{l}\text { Clinical outcomes } \\
\text { at } 365 \text { days }\end{array}$} & & & \multicolumn{2}{|c|}{ HR $(95 \%$ CI $)$} \\
\hline & $\begin{array}{c}\text { Number } \\
\text { events/participants }\end{array}$ & $\begin{array}{c}\text { Number } \\
\text { events/participants }\end{array}$ & Unadjusted & $\begin{array}{l}\text { Adjusted for age, sex } \\
\text { and CVRPII }\end{array}$ \\
\hline Composite MACE\# & $23 / 276(8.3 \%)$ & $123 / 1435(8.6 \%)$ & $0.97(0.62-1.51) *$ & $1.05(0.64-1.73) *$ \\
\hline All-cause death & $10 / 276(3.6 \%)$ & $75 / 1435(5.2 \%)$ & $0.69(0.35-1.33) *$ & $0.82(0.39-1.73) *$ \\
\hline Cardiac death & $9 / 276(3.3 \%)$ & $60 / 1435(4.1 \%)$ & $0.77(0.38-1.55) *$ & $0.95(0.43-2.13) *$ \\
\hline MI & $9 / 276(3.3 \%)$ & $50 / 1435(3.5 \%)$ & $0.93(0.46-1.88) *$ & $1.02(0.47-2.19) *$ \\
\hline Stroke & $5 / 276(1.8 \%)$ & $21 / 1435(1.5 \%)$ & $1.23(0.46-3.26) *$ & $1.05(0.35-3.16) *$ \\
\hline Revascularization & $16 / 276(5.8 \%)$ & $81 / 1435(5.6 \%)$ & $1.00(0.59-1.72) *$ & $1.07(0.62-1.87) *$ \\
\hline \multicolumn{5}{|c|}{$\begin{array}{l}\text { \# MACE was defined as a composite of cardiac death, MI and stroke events. } \\
\text { II CVRF was defined as smoking, history of hypertension, history of diabetes, low-density lipoprotein-cholesterol, high-density lipoprotein-cholesterol, } \\
\text { triglycerides and body mass index. * P-value > 0.20. Abbreviations: CI, confidence intervals; CVRF, cardiovascular risk factor; HR, hazard ratio; } \\
\text { Lp(a), Lipoprotein(a); MACE, major adverse cardiovascular events. }\end{array}$} \\
\hline
\end{tabular}

This article is protected by copyright. All rights reserved. 


\begin{tabular}{|c|c|c|c|c|}
\hline \multicolumn{5}{|c|}{ Table 5 Association between $\operatorname{Lp}(a)$ tertiles and clinical outcomes at one year } \\
\hline & $\begin{array}{l}1^{\text {st }} \text { Tertile } \\
(<2.5-3.1 \mathrm{mg} / \mathrm{dL})\end{array}$ & $\begin{array}{l}2^{\text {nd }} \text { Tertile } \\
(3.1-12.4 \mathrm{mg} / \mathrm{dL})\end{array}$ & $\begin{array}{l}3^{\text {rd }} \text { Tertile } \\
(12.5-132 \mathrm{mg} / \mathrm{dL})\end{array}$ & Per SD increase \\
\hline \multicolumn{5}{|l|}{ Composite MACE } \\
\hline Number events/participants & $56 / 571(9.8 \%)$ & $49 / 572(8.6 \%)$ & $41 / 568(7.2 \%)$ & \\
\hline Crude HR and $95 \% \mathrm{CI}$ & 1 (Ref) & $0.87(0.59-1.27)$ & $0.73(0.49-1.09) * * *$ & $0.94(0.79-1.12)$ \\
\hline Adjusted HR and 95\% CI & 1 (Ref) & $0.89(0.59-1.35)$ & $0.82(0.52-1.28)$ & $0.98(0.82-1.19)$ \\
\hline \multicolumn{5}{|l|}{ All-cause death } \\
\hline Number events/participants & $36 / 571(6.3 \%)$ & $31 / 572(5.4 \%)$ & $18 / 568(3.2 \%)$ & \\
\hline Crude HR and $95 \%$ CI & 1 (Ref) & $0.85(0.53-1.38)$ & $0.49(0.28-0.87)$ & $0.75(0.56-0.99) *$ \\
\hline Adjusted \# HR and 95\% CI & 1 (Ref) & $0.88(0.52-1.50)$ & $0.62(0.33-1.16) * * *$ & $0.82(0.60-1.12)$ \\
\hline \multicolumn{5}{|l|}{ Cardiac death } \\
\hline Number events/participants & $31 / 571(5.4 \%)$ & $23 / 572(4.0 \%)$ & $15 / 568(2.6 \%)$ & \\
\hline Crude HR and 95\% CI & 1 (Ref) & $0.74(0.43-1.26)$ & $0.48(0.26-0.89) *$ & $0.75(0.55-1.02) * *$ \\
\hline Adjusted HR and 95\% CI & 1 (Ref) & $0.79(0.43-1.43)$ & $0.66(0.33-1.31)$ & $0.86(0.61-1.20)$ \\
\hline \multicolumn{5}{|l|}{ Myocardial Infarction } \\
\hline Number events/participants & $22 / 571(3.9 \%)$ & $21 / 572(3.7 \%)$ & $16 / 568(2.8 \%)$ & \\
\hline Crude HR and $95 \%$ CI & 1 (Ref) & $0.95(0.52-1.72)$ & $0.72(0.38-1.37)$ & $0.89(0.67-1.19)$ \\
\hline Adjusted HR and 95\% CI & 1 (Ref) & $0.91(0.48-1.71)$ & $0.75(0.38-1.50)$ & $0.91(0.67-1.24)$ \\
\hline \multicolumn{5}{|l|}{ Stroke } \\
\hline Number events/participants & $8 / 571(1.4 \%)$ & $6 / 572(1.1 \%)$ & $12 / 568(2.1 \%)$ & \\
\hline Crude HR and $95 \%$ CI & 1 (Ref) & $0.74(0.26-2.14)$ & $1.50(0.61-3.66)$ & $1.31(0.99-1.74) * *$ \\
\hline Adjusted HR and 95\% CI & 1 (Ref) & $0.60(0.19-1.88)$ & $1.09(0.40-2.95)$ & $1.24(0.91-1.68)$ *** \\
\hline \multicolumn{5}{|l|}{ Revascularization } \\
\hline Number events/participants & $38 / 571(6.7 \%)$ & $33 / 572(5.8 \%)$ & $26 / 568(4.6 \%)$ & \\
\hline Crude HR and 95\% CI & 1 (Ref) & $0.86(0.54-1.37)$ & $0.66(0.40-1.09) * * *$ & $0.92(0.75-1.14)$ \\
\hline Adjusted HR and 95\% CI & 1 (Ref) & $0.87(0.53-1.43)$ & $0.71(0.42-1.20) * * *$ & $0.95(0.76-1.18)$ \\
\hline
\end{tabular}

This article is protected by copyright. All rights reserved. 
\# Adjusted model included age, sex, smoking, history of hypertension, history of diabetes, low-density lipoprotein-cholesterol, high-density lipoprotein triglycerides and body mass index. * $\mathrm{p}$ value $<0.05, * * \mathrm{p}$ value $0.05-0.10$. *** $\mathrm{p}$ value $0.10-0.20$. $§$ MACE was defined as a composite of cardiac death,

$\mathrm{MI}$ and stroke events. Abbreviations; $\mathrm{CI}$, confidence intervals; HR, hazard ratio; SD, standard deviation

This article is protected by copyright. All rights reserved. 
FIGURES

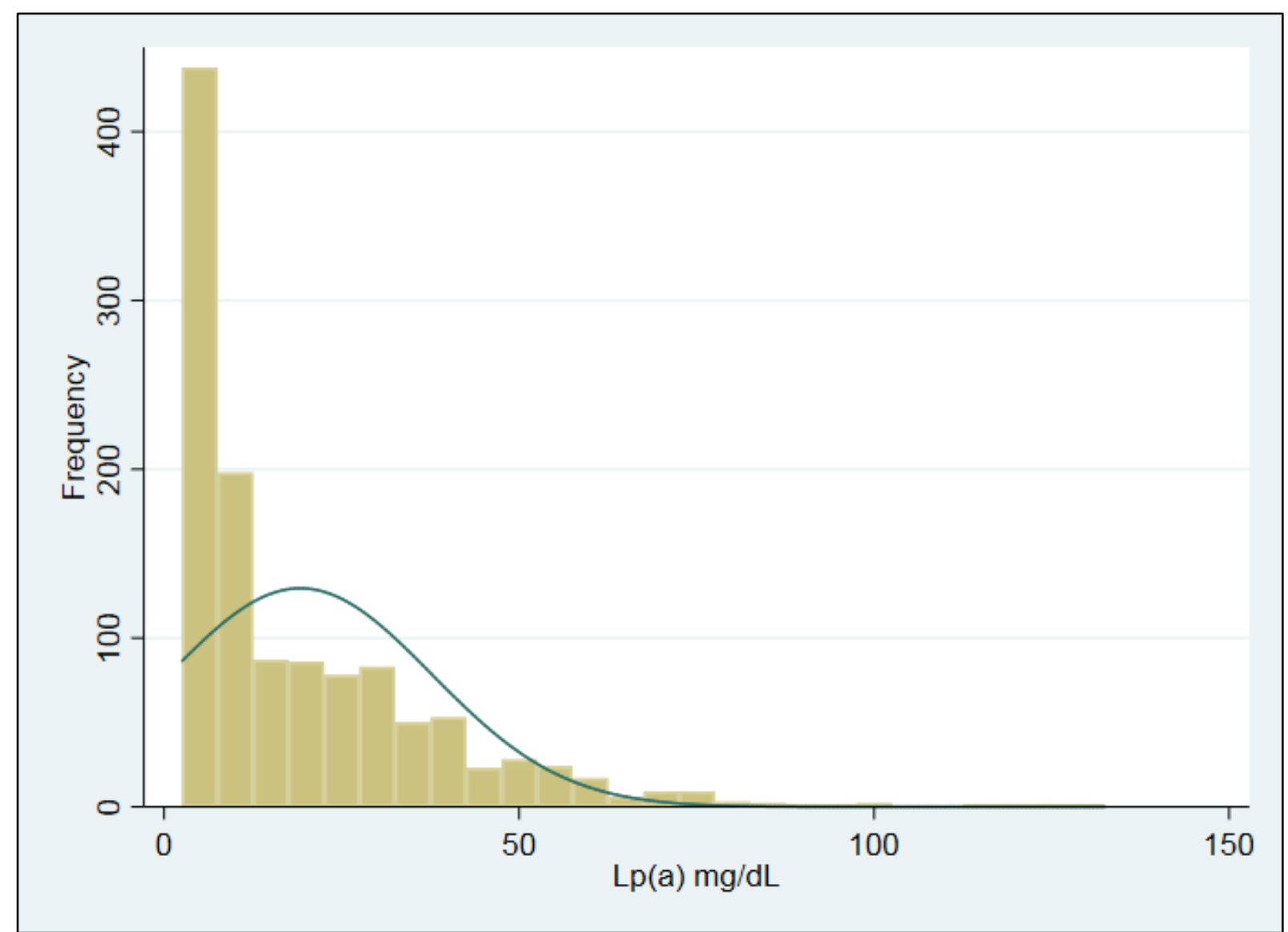

Figure 1 Distribution of Lipoprotein(a) Levels At Time of Angiography in Patients With Acute Coronary Syndrome.

This article is protected by copyright. All rights reserved. 


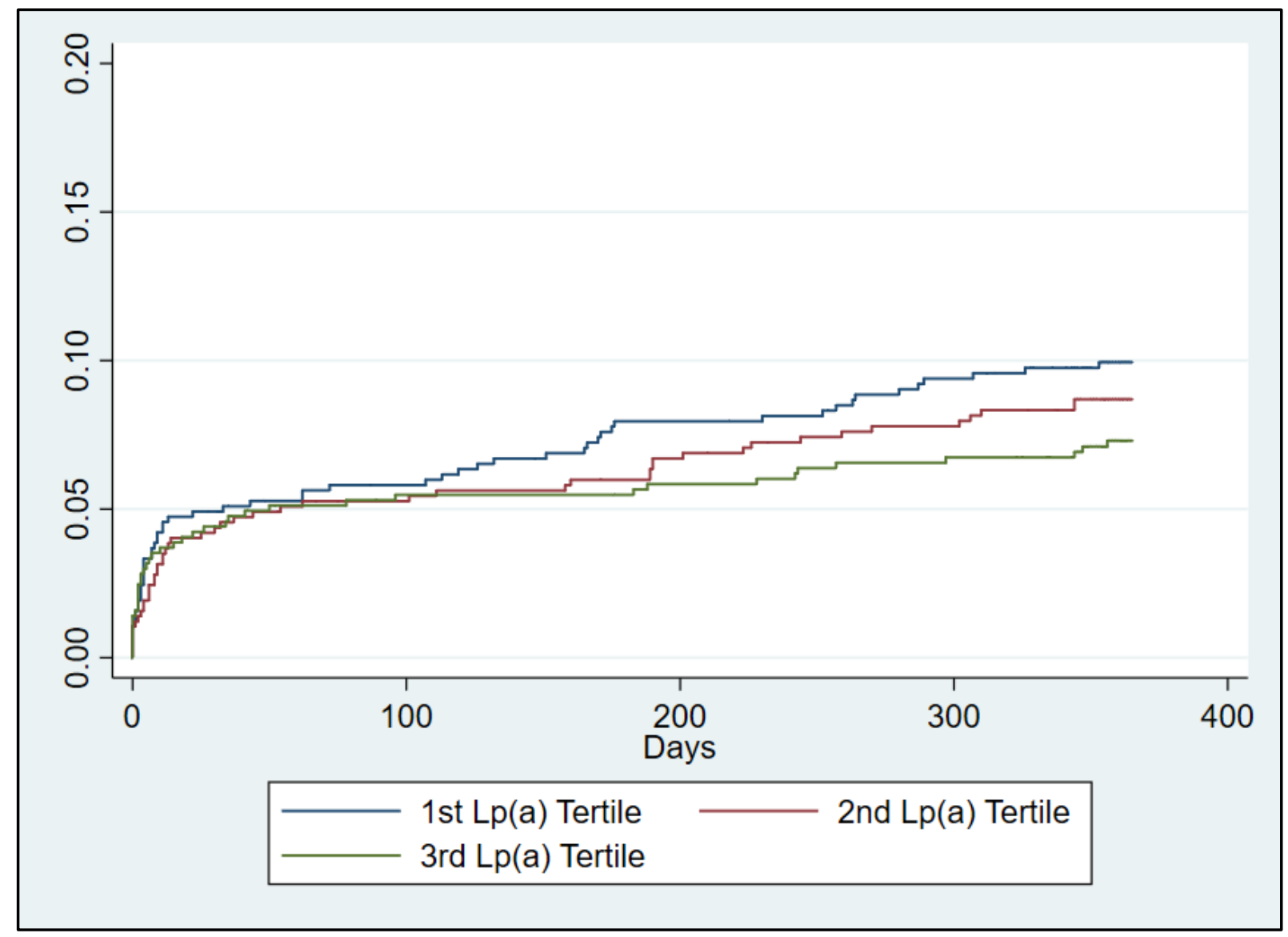

Figure 2 Kaplan-Meier curve for major adverse cardiac events according to $\mathrm{Lp}(\mathrm{a})$ tertiles.

Abbreviations: Lp(a), lipoprotein(a); MACE, major adverse cardiovascular events

This article is protected by copyright. All rights reserved. 